\title{
"Ampliou aquela visão que a gente tinha de música": a educação musical na construção da docência de estagiárias da Pedagogia/UFSM
}

\author{
Kelly Werle*
}

\section{Resumo}

O presente trabalho focaliza a música no processo de construção da docência de estagiárias do curso de Pedagogia da Universidade Federal de Santa Maria. Como referência para este texto, tem-se uma pesquisa de mestrado desenvolvida junto ao PPGE/UFSM e ao grupo Fapem: Formação, Ação e Pesquisa em Educação Musical. O curso de Pedagogia foi o lócus de realização da pesquisa em função do diferencial formativo acerca da educação musical, pois oferta disciplinas obrigatórias de música em sua matriz curricular, além de formação complementar através de oficinas do Programa LEM: Tocar e Cantar. A metodologia definida para a investigação constituiu uma pesquisa participante realizada através de um grupo composto por quatro estagiárias. O texto, inicialmente, apresenta uma discussão sobre a Pedagogia como um curso de formação de professores, direcionando para a formação musical e pedagógico-musical dos pedagogos. Posteriormente, expõe os resultados e análises da referida pesquisa, colocando em pauta duas categorias centrais: "Eu não consigo viver sem música", que trata sobre a música na vida e na formação acadêmico-profissional das estagiárias e "Eu quero poder fazer outras coisas com a música", a qual discorre sobre a música no estágio supervisionado.

Palavras-chave: Pedagogia, Educação Musical, Estágio Supervisionado.

\section{"It has broadened the musical view we had": the musical education into teaching construction by trainers from Pedagogy/UFSM}

\begin{abstract}
The current article focuses on the music into the process of teaching construction by trainers from Pedagogy Course at Santa Maria Federal University. As a reference to this text, there is a masters' degree research carried out at PPGE/ UFSM and at the group Fapem: "Formação, Ação e Pesquisa em Educação Musical. The Pedagogy Course is the research place due to its differential formation related to musical education, because it offers musical compulsory subjects in its curriculum, besides the complementary education through workshops from Programa LEM: Tocar e Cantar. The methodology defined for the study was a participative research, which was carried out by a group of four
\end{abstract}

\footnotetext{
* Doutoranda em Educação no Programa de Pós-Graduação em Educação - Centro de Educação da Universidade
} Federal de Santa Maria (UFSM). Santa Maria, Rio Grande do Sul, Brasil. 


\title{
Kelly Werle
}

trainers. The text, initially, brings a discussion upon Pedagogy as a course for teacher education, directing to music and music-pedagogical education of the pedagogues. Posteriorly, it shows the research results and analyses, detaching two central categories: "I cannot live without music", which deals with music in life and in the professional-academic education of the trainers and "I want to do other things with music", which discusses on the music into the supervising training.

Keywords: Pedagogy, Musical Education, Supervising Training.

\section{A música no curso de Pedagogia/UFSM}

O curso de Pedagogia, desde o início de sua criação no Brasil pelo Decreto-Lei 1.190 em 4 de abril de 1939, apresentou diversas modificações quanto à sua identidade, sendo alvo de muitos questionamentos e problematizações referentes aos seus objetivos, à estrutura curricular, ao tipo de profissional que visava formar, bem como, ao valor e à inserção deste profissional no campo de trabalho (BRZEZINSKI, 2008). Inicialmente, formava o técnico e o pesquisador em educação. Contudo, com o passar do tempo, devido a influências sociais e políticas, o curso distanciou-se dessa perspectiva e foi sendo delineado como um curso direcionado à formação de professores.

Em 2006, foram instituídas as diretrizes curriculares nacionais para o curso de Pedagogia (DCNP), as quais passaram a nortear e definir o curso. Conforme as DCNP

\begin{abstract}
O curso de Licenciatura em Pedagogia destina-se à formação de professores para exercer funções de magistério na Educação Infantil e nos Anos Iniciais do Ensino Fundamental, nos cursos de Ensino Médio, na modalidade Normal, de Educação Profissional na área de serviços e apoio escolar e em outras áreas nas quais sejam previstos conhecimentos pedagógicos (BRASIL, 2006).
\end{abstract}

Com as diretrizes, instituiu-se a docência como parte importante da formação na Pedagogia, sendo um dos objetivos do curso formar prioritariamente o professor de educação infantil e anos iniciais do ensino fundamental. Parte dos cursos de Pedagogia já vinha com uma trajetória histórica na formação de professores e, segundo Brzezinski (2008, p. 220), com as DCNP podem ser apontadas algumas possibilidades, como "a garantia de uma base comum nacional - formação para a docência, a extinção das habilitações e a ampliação do campo do exercício profissional".

No que diz respeito à formação no curso de Pedagogia, as DCNP apontam que o egresso deve estar apto a "ensinar Língua Portuguesa, Matemá- 
"Ampliou aquela visão que a gente tinha de música": a educação musical na construção da docência de estagiárias da Pedagogia/UFSM

tica, Ciências, História, Geografia, Artes, Educação Física, de forma interdisciplinar e adequada às diferentes fases do desenvolvimento humano" (BRASIL, 2006). Para o contexto deste artigo, em específico, destaca-se a formação prevista em Artes.

Conforme os parâmetros curriculares nacionais para o ensino fundamental (PCNs), Arte é uma área que envolve múltiplas linguagens, Artes Visuais, Dança, Música e Teatro. Além disso, mediante a aprovação da Lei 11.769/ 2008, fica estabelecida a obrigatoriedade da música como conteúdo, não exclusivo, do componente curricular Arte da educação básica (BRASIL, 2008).

Recentemente, a Resolução CNE/CEB de nำ7/2010, que fixa diretrizes curriculares nacionais para o ensino fundamental de 9 (nove) anos, orienta em seu artigo 31 , que "do $1^{\circ}$ ao $5^{\circ}$ ano do ensino fundamental, os componentes curriculares Educação Física e Arte poderão estar a cargo do professor de referência da turma, aquele com o qual os alunos permanecem a maior parte do período escolar, ou de professores licenciados nos respectivos componentes" (BRASIL, 2010). No parágrafo segundo deste artigo, orienta-se que nos casos em que esses componentes curriculares sejam desenvolvidos por professores com licenciatura específica (conforme Parecer CNE/CEB nํ2/2008), deve ser assegurada a integração com os demais componentes trabalhados pelo professor de referência da turma.

Todavia para que os egressos da Pedagogia tenham condições de trabalhar com a música, visto que trabalham com a totalidade dos conhecimentos de modo articulado, é necessário que desenvolvam experiências formativas nessa área. Algumas pesquisas, a exemplo de Figueiredo (2003), Furquim (2009), Bellochio e Figueiredo (2009) têm buscado investigar qual formação, acerca da música, tem sido proporcionada por parte dos cursos de Pedagogia no sul do Brasil. Os resultados têm demonstrado que essa formação é, muitas vezes, ausente ou escassa, minimizando as possibilidades de realização musical na docência de seus egressos.

Por outro lado, há alguns cursos de Pedagogia que já constituem trajetória histórica na formação musical e pedagógico-musical de seus graduandos, como é o caso da UFSM que, desde 1984, quando passou a formar professores para as antigas habilitações em séries iniciais e pré-escola, integra disciplinas de educação musical em sua matriz curricular. Oesterreich (2010) pesquisou a trajetória histórica das disciplinas de música na Pedagogia/ UFSM, de 1984 a 2008, e constatou que

a inserção da música na Pedagogia teve influência resultante da presença de um conjunto de professores, que se encontravam vinculados ao Departamento de Metodologia do Ensino e responsáveis pelas diferentes Licenciaturas em Artes - Música, Artes Plásticas e Tea- 
tro, cujas vozes e experiências foram determinantes para esta alteração (OESTERREICH, 2010, p.143).

Segundo a autora, as disciplinas passaram por várias modificações relacionadas às concepções sobre formação de professores e o ensino de música, as quais possibilitaram maneiras diferentes de conceber a formação musical do pedagogo e suas funções no espaço de sala de aula. Após ter passado por reformulações e adaptações curriculares para atender às DCNP, o curso oferta atualmente duas disciplinas obrigatórias de educação musical: Educação Musical, com 60h e Educação Musical para a Infância, com 30h.

Embora o curso de Pedagogia da UFSM tenha uma trajetória formativa em educação musical, tem-se constatado que as disciplinas não são a garantia de que as futuras professoras venham a trabalhar com essa área do conhecimento na docência (SPANAVELLO, 2005).

Desta forma, em 2003, a fim de ampliar as vivências musicais das alunas, foi criado o "Programa LEM: Tocar e Cantar" que vem ofertando gratuitamente oficinas musicais e discussões acerca da música na escola. Correa (2008) aponta que, se as disciplinas curriculares de educação musical forem complementadas com a participação nas oficinas do "Programa LEM: Tocar e Cantar", favorecerão a formação musical e pedagógico-musical das futuras professoras, de modo que elas se sintam mais confiantes e percebam maiores possibilidades de realizações musicais em seu trabalho docente.

As ações do Programa são realizadas de maneira compartilhada entre docentes, mestrandos e, principalmente, licenciandos em música. Assim, o Programa constitui espaço formativo, não somente para acadêmicos da Pedagogia, mas também, para graduandos do curso de Música (SCHWAN, 2009), os quais exercem atividades vinculadas à docência.

A oferta das oficinas é variada, dependendo da demanda e da equipe de trabalho. Nesse sentido, no ano letivo de 2011, foram desenvolvidas oficinas de flauta doce, violão e canto coral. Destaca-se a participação do Laboratório de Educação Musical (LEM) na Jornada Acadêmica Integrada da UFSM, em que realizou diversas oficinas: educação musical e arte contemporânea, educação musical para bebês, educação musical e tecnologia, educação musical e educação especial, educação musical em projetos sociais e educação musical e canções de brincar.

Outra iniciativa criada em 2005, na UFSM, buscando expandir ações formativas em educação musical é o "Programa SOM: Formação, Assessoria e Orientação em Música", que, dentre outras frentes de trabalho, visa orientar professores em serviço em ações ligadas à música, contribuindo, assim, com a formação continuada de professores da educação infantil e anos iniciais. 
"Ampliou aquela visão que a gente tinha de música": a educação musical na construção da docência de estagiárias da Pedagogia/UFSM

Neste contexto, a UFSM tem sido reconhecida pelo potencial formativo acerca da música no curso de Pedagogia, favorecendo a criação de um ambiente profícuo para a construção e realização de pesquisas teóricas e práticas referentes à formação musical e pedagógico-musical de professores da educação infantil e anos iniciais, tais como Bellochio (2000), Spanavello (2005), Pacheco (2005), Correa (2008), dentre outras.

\section{A pesquisa acerca da música no estágio de graduandas da Pedagogia}

O estágio supervisionado é um momento relevante da formação acadêmico-profissional do curso de Pedagogia. Nesse momento, tem-se buscado aproximar o futuro professor e o campo de trabalho, de modo a contribuir com a organização e a implementação de atividades pedagógicas, bem como, com a reflexão e a problematização da realidade escolar. É no estágio que os graduandos "enfrentam o desafio de articular os conhecimentos construídos até então, fora e dentro do contexto universitário, com as necessidades cotidianas de sala de aula" (BELLOCHIO; BEINEKE, 2007, p.74).

Neste sentido, buscou-se realizar a pesquisa com graduandas da Pedagogia, ${ }^{1}$ que estavam cursando a disciplina de Estágio Supervisionado na Educação Infantil e Anos Iniciais, com o objetivo de investigar como as estagiárias potencializavam a música no processo de construção da docência.

O desenho metodológico da investigação compõe uma pesquisa participante, delineada após ter sido constatada, através de um estudo exploratório, a necessidade de organizar um grupo de apoio para que as acadêmicas pudessem trabalhar com a música durante a realização do estágio supervisionado.

Segundo Brandão (1999), a participação demanda um compromisso do pesquisador que subordina o próprio projeto científico de pesquisa às necessidades e aos contextos dos grupos sociais cuja situação de classe, cultura ou história se quer conhecer porque se quer agir. Em decorrência disso, na pesquisa participante, "pesquisadores e pesquisados são sujeitos de um mesmo trabalho comum, ainda que com situações ou tarefas diferentes" (BRANDÃO, 1999 p. 11).

A pesquisa foi realizada por intermédio de um grupo ${ }^{2}$ composto pela pesquisadora e quatro estagiárias, o qual se reunia semanalmente, no período de quatro meses, com o objetivo de problematizar e propor alternativas para o processo de planejamento, registro, reflexão e avaliação das atividades musicais desenvolvidas durante o estágio. Além disso, discutia-se sobre a articulação da música com os demais conteúdos, buscando estratégias para proporcionar atividades que pudessem estar relacionadas e contextualizadas como um todo.

Concomitantemente aos encontros, foram realizadas observações participantes ${ }^{3}$ nas turmas em que as estagiárias desenvolveram os estágios, 


\section{Kelly Werle}

com a finalidade de acompanhar as atividades musicais e compreender como elas desenvolviam a música junto aos alunos. Durante a participação na pesqui$\mathrm{sa}$, as estagiárias foram estimuladas a realizar registros diários ${ }^{4}$ sobre suas percepções, sentimentos, dificuldades ou conquistas com relação à música no processo de construção da docência.

Desse modo, através do acompanhamento sistemático das estagiárias, buscou-se conhecer suas concepções com relação à música no e para o estágio supervisionado, problematizar a música em suas práticas pedagógicas e refletir acerca da música no conjunto de conhecimentos que compõe a docência.

A discussão dos resultados da pesquisa foi organizada em cinco categorias. Neste artigo, serão apresentadas as análises relacionadas a duas categorias centrais, as quais se referem à música na vida e na formação acadêmico profissional das estagiárias e à música no estágio supervisionado.

\section{"Eu não consigo viver sem música": a música na vida e na formação acadêmico-profissional das estagiárias}

A música como experiência social se faz presente em variados momentos do cotidiano das participantes. Elas relatam gostar de ouvir e dançar, com frequência, músicas da mídia e/ou músicas antigas que reportam a momentos vivenciados no passado. Percebe-se que estabelecem uma ligação forte entre música e sentimento, pois facilmente relacionam determinadas músicas com momentos que vivenciaram ou que estão passando no presente, e as classificam como sendo músicas alegres, tristes, relaxantes, dançantes, etc.

As participantes relembram vivências tidas com a música em períodos da infância, nas quais se destacam o fator afetivo. Recordam de momentos experienciados com a família, como acalantos cantados por mães e avós, músicas que os pais ouviam na rádio, brincadeiras realizadas por meio de cantigas e, até mesmo, músicas executadas por familiares que sabiam tocar instrumento musical. "Quando eu era criança, meu tio tocava gaita e todas as tardes nós íamos assisti-lo tocar. O sonho da minha mãe era que eu e meu irmão fizéssemos um trio musical" (Anna). ${ }^{5}$

Por vezes, as estagiárias traziam, à tona, o desejo que tiveram outrora de aprender a tocar um instrumento musical (o violão em grande parte das vezes), mas relatavam com frustração as poucas oportunidades que tiveram ou a ausência das habilidades que julgam necessárias. Apenas uma das participantes fez menção à experiência de ter participado de um coral, bem como a realização de aulas particulares de canto. As demais, embora demonstrassem prazer e alegria ao falar sobre música, tinham receio de não terem "dom" ou habilidades necessárias para trabalhar com música junto aos alunos, sendo que o contato mais formal com a música ocorreu nas disciplinas de educação musical da Pedagogia. 
"Ampliou aquela visão que a gente tinha de música": a educação musical na construção da docência de estagiárias da Pedagogia/UFSM

Refletindo sobre a questão do "dom", entende-se que o fazer musical não é algo concedido naturalmente sem influência do meio ou esforço próprio. Fazer música implica em estudo, esforço e dedicação como em qualquer outra área do conhecimento. A música não é um dom concedido a uns e negado a outros, o que ocorre é que, no decorrer das trajetórias de vida, as pessoas possuem maiores ou menores oportunidades de estar desenvolvendo-se musicalmente. Portanto, não existe uma pessoa amusical, pois "a musicalidade é uma característica da espécie humana e [...] todos os seres humanos estão aptos a se desenvolverem musicalmente" (FIGUEIREDO; SCHMIDT, 2008).

As graduandas também mencionaram as experiências musicais que tiveram ao longo do processo de escolarização, sendo mais frequentes, nos anos iniciais, através de apresentações em datas comemorativas, brincadeiras de roda e jogos corporais rítmicos realizados entre colegas durante o recreio. Na adolescência, destaca-se o valor social atribuído à música; pois, por meio da partilha de determinados gostos musicais, se compunham os grupos de amizades. As estagiárias relembravam cantores e músicas preferidas, bem como o que costumavam fazer enquanto ouviam. Neste período de adolescência, uma das estagiárias começou a participar de uma invernada artística, onde passou a apreciar e atribuir significado às músicas nativistas, o que perdura até o momento presente.

Neste contexto, entende-se que as vivências musicais tidas na infância e na adolescência em um coletivo social, internalizadas pela sua significação pessoal, mesmo que não sejam formais, contribuem na construção de sentidos relacionados à música. Talvez, a presença marcante de tais experiências nas trajetórias de vida das graduandas tenha contribuído para e influenciado sobre a participação delas na pesquisa.

As vivências musicais prévias das alunas são fundamentais para que, durante as disciplinas de educação musical na Pedagogia, elas possam estabelecer relações com suas próprias experiências, buscando a ressignificação delas. Conforme Wazlawick (2006, p.13), "As emoções e os sentimentos, integrantes da atividade humana, junto ao agir e ao pensar, configuram a construção dos significados singulares da música, de acordo com a vivência do sujeito e de sua própria reflexão acerca de si e de suas experiências".

Durante a realização do curso de Pedagogia, através dos relatos das alunas, também foi possível perceber alguns movimentos de buscar formação musical; pois, além das disciplinas, elas participaram de oficinas do Programa LEM: Tocar e Cantar e de recitais promovidos pelo CE, como o show da Pandorga da Lua. ${ }^{6}$ Unindo-se a essas vivências, as participantes da pesquisa faziam parte de uma turma de alunas que, espontaneamente, organizaram um coral para homenagear aos pais na cerimônia de colação de grau. Para tanto, convidaram uma licencianda do curso de Música da UFSM para reger e coordenar os ensaios que ocorreram semanalmente, no período de cinco meses que antecederam à formatura. 


\section{Kelly Werle}

A partir dessa situação, é possível refletir sobre a relevância da educação musical na formação das alunas do curso de Pedagogia. Não se pretende atribuir o mérito desse coral unicamente a essa formação; entretanto, se não houvesse todo o movimento de valorização e de construção de conhecimentos acerca da música, talvez não tivesse espaço para experiências como de canto coral e nem para valorização e reconhecimento das alunas.

Neste contexto, entende-se que a música tem um sentido e um significado para a vida das participantes da pesquisa. Provavelmente, esse seja um diferencial, o fato de gostar de música e ter internalizações pré-formação com relação à área, ainda que decorrentes de aprendizagens não-formais.

\section{"Eu quero poder fazer outras coisas com a música": a música no estágio supervisionado}

Desde os primeiros encontros com o grupo, já foi possível perceber que as participantes apresentavam a concepção de que a música é um conhecimento que deve ser desenvolvido junto aos alunos. Por outro lado, não possuíam clareza em relação aos seus conteúdos específicos. Essa dificuldade de compreender e de significar tais conteúdos se deve à carência de experiências mais profundas e duradouras acerca da música, para que, assim, as alunas estabeleçam relações significativas, vinculando os conteúdos às suas próprias experiências nessa área.

Nesse contexto, embora as alunas desejassem trabalhar com a música, não apenas a utilizando como recurso metodológico, elas tinham dificuldades em organizar e planejar atividades que envolvessem seus conteúdos, o que passa por planejamento e avaliação de seu trabalho na relação com o desenvolvimento dos alunos.

Como não dominavam os elementos específicos, as participantes pensavam que não conseguiriam promover nada do que é possível de ser realizado em uma aula de música. Clara relatou logo no início dos encontros do grupo: "Eu me sinto muito insegura porque não domino os conteúdos específicos da música". Desta forma, inicialmente, tinham restrições em trabalhar com a música, pois não queriam a utilizar apenas como instrumento para o aprendizado de outros conteúdos ou como recurso metodológico.

Com o decorrer dos encontros e das discussões realizadas acerca das práticas musicais no conjunto dos planejamentos de suas aulas, houve um maior envolvimento do grupo no que diz respeito à organização e ao planejamento das atividades musicais. As participantes passaram a ter uma relação mais estreita e tranquila com a música, buscando maiores possibilidades de atividades musicais com os alunos. "Eu quero poder fazer outras coisas com a música. Não quero só colocar a música e perguntar quem é que canta, que instrumentos tem, cantar forte, cantar fraco" (Anna). 
"Ampliou aquela visão que a gente tinha de música": a educação musical na construção da docência de estagiárias da Pedagogia/UFSM

Com relação à organização das atividades musicais, as alunas destinavam um espaço do seu planejamento semanal para trabalhar com a música. Percebeu-se que na educação infantil havia mais espaço para implementar atividades musicais do que nos anos iniciais, em função do projeto de escolarização imposto aos alunos centrado no cumprimento de uma lista de conteúdos, na qual a música ainda não fazia parte.

Contudo, as estagiárias procuraram superar os obstáculos e criar um espaço para a música nos anos iniciais. "A música foi um dos aspectos mais interessantes dos dois estágios. [...] Ao contrário do que eu imaginava antes do estágio, nos anos iniciais, foi possível explorar tanto ou mais música que na educação infantil” (Anna).

As atividades musicais realizadas pelas participantes da pesquisa variaram entre apreciar, cantar, percutir, executar utilizando objetos sonoros ou instrumentos musicais, trabalhar com a expressão corporal e criar paródias. Ocorreram também atividades relacionadas a histórias sonorizadas, a jogos rítmicos de mãos e copos, a confecção de instrumentos musicais, a bingos sonoros, a jogos da memória sonoros, etc.

Durante os processos de planejamento e avaliação das atividades musicais, as estagiárias, constantemente, apresentavam a preocupação em potencializar uma aula de música e não apenas uma aula com música. Diversas vezes, elas próprias se questionavam: "Isso que estou fazendo é uma aula de música?"

Esse questionamento associa-se a ideia de que elas consideravam a música algo distante de suas reais possibilidades de interagir com esse campo. A falta de uma aproximação maior com a área, distinta de mero entretenimento, alimentava uma concepção, um tanto tradicional, acerca do ensino da música; o que dificultava, por vezes, o exercício de planejamento de atividades. Desse modo, quando visualizavam algumas possibilidades concretas, surpreendiamse com as construções que eram realizadas coletivamente no grupo de estagiárias.

A organização e a realização de atividades musicais foram pautadas por critérios que nortearam o desenvolvimento de cada uma das estagiárias no processo de compreensão e inserção da música em suas atividades docentes. Luiza e Anna, nos encontros iniciais, demonstravam-se apreensivas por entender que o fato de não dominarem algum instrumento poderia impedir a inserção da música em suas práticas. Apesar de superarem, parcialmente, a necessidade do domínio de um instrumento por parte do professor, buscando outras formas de potencializar a música junto aos alunos, frequentemente, trabalhavam com a utilização e exploração de instrumentos musicais, pois atribuíam aos mesmos a condição necessária para e característica de uma aula de música. 


\section{Kelly Werle}

Entende-se também que isso decorre da necessidade de materialização da música; em outras palavras, na medida em que se leva um instrumento musical para a turma, ilusoriamente, tem-se a ideia de que assim também se está levando a música, como se a música estivesse a priori no instrumento musical.

De modo geral, desenvolver atividades musicais no estágio exigiu a dedicação, a persistência e a superação por parte das participantes. O fato de as estagiárias terem vivências musicais internalizadas, gostarem da música e acreditarem em sua importância no contexto escolar fez com que não desistissem de trabalhar com essa área, mesmo encontrando inúmeras dificuldades. Destaca-se um registro realizado após uma sequência de atividades musicais: "Penso que tive dificuldades em conduzir essa aula de música, pois tenho poucas vivências deste tipo. Mas adoro música, vejo que os alunos também gostam, e por isso não vou desistir" (Clara).

\section{Algumas considerações}

A inserção da música, na construção da docência das estagiárias, vinculou-se às concepções e às vivências que cada uma delas construiu sobre música e sobre seu ensino, visto que se percebeu uma profunda relação com as vivências musicais tidas na infância e na adolescência, as quais influenciaram o maior ou o menor envolvimento delas com música durante o estágio.

As experiências formativas, mediante as disciplinas e o Programa, acrescidas das problematizações e mediações realizadas no grupo proporcionaram a ressignificação de variados aspectos. Contudo, destaca-se a importância das significações anteriores construídas acerca da música, as quais possibilitaram essas reconstruções. Constata-se que, durante o estágio, as graduandas levam para sua prática tudo aquilo que Ihes é significativo. Uma vez que tenham construído significados acerca da música, essa terá grandes chances de se fazer presente em sua docência.

O trabalho com a música, no estágio, foi resultante de intensa construção e reflexão, iniciadas nas disciplinas de educação musical, perpassadas pelas oficinas do "Programa LEM: Tocar e Cantar" e aprofundadas nos encontros do grupo. Salienta-se a relevância do grupo de trabalho, o qual serviu como motivação para o desenvolvimento de planejamentos que envolvessem música durante o estágio supervisionado. "Se não fosse o grupo, eu acho que eu não teria trabalhado com a música no meu estágio" (Luiza). Nos encontros do grupo, as estagiárias partilhavam experiências, angústias, anseios, e mais do que planejar e refletir sobre as atividades musicais, elas se apoiavam mutuamente, adquirindo a coragem necessária para que pudessem superar o desafio de trabalhar com essa área do conhecimento.

Não é aquela coisa cansativa, não é aquele encontro chato. Eu gosto, acho legal ouvir o que as colegas fa- 
“Ampliou aquela visão que a gente tinha de música": a educação musical na construção da docência de estagiárias da Pedagogia/UFSM

zem. [...] Contribui para eu pensar e até criar alguns conceitos e algumas ideias. Tu vês cada um trazer as suas experiências. Eu acho que isso contribui muito. Eu gosto desta troca que é uma oportunidade que a gente tem nesse projeto. (LAURA, ESE)

Neste sentido, o estar junto com o grupo possibilitou que se criassem vínculos de amizade e de cumplicidade entre todas as envolvidas, de modo que, o grupo se tornou um dispositivo formativo que contribuiu para a problematização, reflexão e realização, não somente da música no estágio, mas do estágio supervisionado de modo geral.

De acordo com Oliveira (2009, p. 117), "é na convivência, no estarjunto, na relação com o outro, nas reuniões, nos encontros, nos agrupamentos, na efervescência festiva, ou seja, no momento passado com os outros que se estabelecem os vínculos, um pertencer múltiplo". Entende-se que o grupo é um elemento formativo que possibilita através do diálogo, socialização, partilha e escuta, acessar dimensões subjetivas que tangem a construção da docência mediadas, assim, pela coletividade.

Com o decorrer dos encontros, percebeu-se que houve um avanço significativo na forma como as participantes passaram a interagir e a estabelecer relações com a música. Em especial pelo fato de que, no grupo, sentiramse confiantes, em um primeiro momento, a expor aspectos relacionados às suas limitações, o que as aproximou, favorecendo o sentimento de pertença de grupo. Para então, descobrir juntas possibilidades para superar as questões necessárias e, assim, realizar um trabalho envolvendo a música nos estágios.

Neste contexto, destaca-se, novamente, a relevância da formação musical e pedagógico-musical proporcionada pelo curso de Pedagogia da UFSM a partir de experiências disciplinares e não disciplinares. Já que é o meio pelo qual, muitas graduandas, a exemplo das quatro participantes da pesquisa, passam a ter um contato formal com a educação musical, possibilitando a discussão da atuação do pedagogo com música, bem como a realização de práticas musicais.

Desta forma, experiências formativas, na Pedagogia, acerca da música são imprescindíveis na busca para atender a legislação em vigor acerca da formação prevista em Artes, DCNP (BRASIL, 2006), bem como sobre o ensino de Música, na escola, como conteúdo obrigatório do componente curricular Arte (Lei n. 11.769/2008).

Como contribuição da pesquisa, essa formação poderia ser complementada e ampliada através de grupos de orientação às estagiárias, já que as orientações que são realizadas nos estágios supervisionados não tratam da especificidade de algumas áreas, como a Música. 
Kelly Werle

\section{Referências}

BELLOCHIO, C. R. A educação musical nas séries iniciais do ensino fundamental: olhando e construindo junto às práticas cotidianas do professor. Porto Alegre: UFRGS, 2000. Tese (Doutorado em Educação) - Universidade Federal do Rio Grande do Sul, Programa de Pós-Graduação em Educação, 2000.

BELLOCHIO, C. R.; FIGUEIREDO, S. L. F. de. Cai, cai balão... Entre a formação e a práticas musicais em sala de aula: discutindo algumas questões com professoras não especialistas em música. In: Revista Música na Educação Básica. Associação Brasileira de Educação Musical, Porto Alegre, v. 1, n. 1, out. 2009. p. 36-45.

BELLOCHIO, C. R.; BEINEKE, V. A mobilização de conhecimentos práticos no estágio supervisionado: um estudo com estagiários de música da UFSM/RS e da UDESC/SC. Música Hodie, Goiás, v. 7, n. 2, 2007. p. 73-88.

BRANDÃO, C. R. (Org.). Pesquisa participante. São Paulo: Brasiliense, 1999.

BRASIL, Novas Diretrizes Curriculares para o Ensino Fundamental de 9 anos. RSL N.7, de 14 de dezembro de 2010, sobre o ensino fundamental. Disponível em: <http://www.cne.gov.br.html>. Acesso em: fev. 2011.

BRASIL, Diretrizes curriculares para o curso de Pedagogia, resolução CNE/ CP n. 1, de 15 de maio de 2006. Disponível em: <http://portal.mec.gov.br/cne/ arquivos/pdf/rcp01_06.pdf>. Acesso em: jun. de 2009.

BRASIL, Lei de Diretrizes e Bases da Educação, LDB, Lei n. 11.769/2008. Disponível em: <http://www.planalto.gov.br/ccivil_03/_Ato2007-2010/2008/Lei/ L11769.htm>. Acesso em: fev. de 2010.

BRZEZINSKI, I. Memória, cultura, identidades e desafios do curso de Pedagogia. In: ENCONTRO NACIONAL DE DIDÁTICA E PRÁTICA DE ENSINO, 14., 2008, Porto Alegre, RS. Trajetórias e processos de ensinar e aprender: políticas e tecnologias. Porto Alegre: ENDIPE, 2008. p. 205-226.

CORREA, A. N. Programa LEM: Tocar e Cantar: um estudo acerca de sua inserção no processo músico-formativo de unidocentes da Pedagogia/UFSM. Dissertação (Mestrado em Educação) - Universidade Federal de Santa Maria, Santa Maria, 2008.

FIGUEIREDO, S. L. F. de. A formação musical nos cursos de pedagogia. In: ENCONTRO NACIONAL DAASSOCIAÇÃO BRASILEIRA DE EDUCAÇÃO MUSICAL, 12., 2003, Florianópolis, SC. Anais... Florianópolis: ABEM, 2003. Disponível em CD-ROM.

FIGUEIREDO, S. L. F. de.; SCHMIDT, L. M. Refletindo sobre o talento musical na perspectiva de sujeitos não-músicos. In: SIMPÓSIO DE COGNIÇÃO E ARTES MUSICAIS, 4., 2008, São Paulo, SP. Anais... São Paulo: SIMCAM, 2008. 
"Ampliou aquela visão que a gente tinha de música": a educação musical na construção da docência de estagiárias da Pedagogia/UFSM

Disponível em: <http://www.fflch.usp.br/dl/simcam4/anais_simcam4.htm>. Acesso em: abr. de 2009.

FRANCO, M. L. P. B. Análise de conteúdo. 2. ed. Brasília: Líber Livro, 2007.

FURQUIM, A. S. dos S. A formação musical de professores em cursos de Pedagogia: um estudo das universidades públicas do Rio Grande do Sul. Dissertação (Mestrado em Educação) - Universidade Federal de Santa Maria, Santa Maria, 2009.

OESTERREICH, F. A história da disciplina de música no curso de Pedagogia da UFSM (1984-2008). Dissertação (Mestrado em Educação) - Universidade Federal de Santa Maria, Santa Maria, 2010.

OLIVEIRA, V. F. de. O grupo como dispositivo de formação: conhecendo trajetos na educação superior. In: ISAIA, S. M. de A.; BOLZAN, D. P. de V. (Orgs.). Pedagogia universitária e desenvolvimento profissional docente. Porto Alegre: EDIPUCRS, 2009, p. 101-120.

PACHECO, E. G. Educação musical na educação infantil: uma investigação-ação na formação e nas práticas das professoras. Santa Maria: UFSM, 2005. Dissertação (Mestrado em Educação) Programa de Pós-Graduação em Educação, Universidade Federal de Santa Maria, 2005.

SCHWAN, I. C. Programa LEM: Tocar e Cantar: um lugar de formação e atuação acadêmico profissional. Dissertação (Mestrado em Educação) - Universidade Federal de Santa Maria, Santa Maria, 2009.

SPANAVELLO, C. da S. A educação musical nas práticas educativas de professores unidocentes: um estudo com egressos da UFSM. Dissertação (Mestrado em Educação) - Universidade Federal de Santa Maria, Santa Maria, 2005.

WAZLAWICK, P. Quando a música entra em ressonância com as emoções: significados e sentidos na narrativa de jovens estudantes de musicoterapia. Revista Científica/FAP, Curitiba, v. 1, jan./dez. 2006. Disponível em: <http:// www.fap.pr.gov.br/arquivos/File/Revistacientifica1/PATRICIA_WAZLAWICK.pdf>. Acesso em: 12 mar. 2010.

${ }^{5}$ Os nomes utilizados são fictícios visando preservar a identidade das estagiárias, conforme padrões exigidos pelo Comitê de Ética em Pesquisa CEP/UFSM, no qual o referido projeto está registrado sob o n. 0173.0.243.000-09.
} 


\section{Kelly Werle}

${ }^{6}$ Pandorga da Lua é um projeto educativo que compõe um musical voltado ao público infantil, constituído a partir de poesias do escritor Jaime Vaz Brasil que foram musicadas por Ricardo Verissimo Freire em ritmos da cultura gaúcha. Esse projeto foi aprovado no Ministério da Cultura, Artigo 18, para itinerar no interior do Rio Grande do Sul, em municípios que pouco recebem espetáculos culturais. Além disso, o grupo também já se apresentou em Rivera e Montevideu no Uruguai, e na Guiana Francesa. Fonte: <www.chilism.com.br>

\section{Correspondência}

Kelly Werle - Travessa Monteiro Lobato, 155 apto 501 - CEP: 97015-420 Centro - Santa Maria, Rio Grande do Sul, Brasil.

E-mail: kelly_werle@hotmail.com

Recebido em 27 de outubro de 2011

Aprovado em 19 de dezembro de 2011 